\title{
RESULTADOS ECONÔMICO, MONETÁRIO E DE RECURSOS FINANCEIROS
}

\section{YUICHI RICHARD TsUKamoto*}

O Professor Robert Johnson, no seu livro Administração Financeira, compara o papel do administrador financeiro numa emprêsa (microeconomia) com o do sistema de preço numa economia de livre iniciativa (macroeconomia). Ambos têm sua função principal de alocação de recursos disponíveis para obter máxima satisfação. ${ }^{1}$ Para uma emprêsa, satisfação máxima significa dois objetivos:

- aumentar o mais possível a sua riqueza (rentabilidade e retôrno);

manter em ótimo estado a sua "saúde" financeira (liquidez).

A companhia poderá ser bastante rica, possuindo elevados valôres de ativos fixos, mas, exatamente por esta razão, não poderá liquidar seus compromissos a curto prazo por causa da baixa liquidez financeira. Por outro lado, a companhia poderá manter um nível alto de numerários para proteger sua reputação creditícia sôbre seus compromissos, mas, exatamente por esta filosofia conservadora. ela não investe em instalações e maquinarias suficientemente para acompanhar o desempenho do mercado. $O$ administrador financeiro, em ambos os casos, falha por

* Professor contratado do Departamento de Contabilidade, Finanças e Contrôle da Escola de Administração de Emprêsas de São Paulo, da Fundação Getúlio Vargas, e Diretor-Controlador da Companhia Paulista de Adubos (COPAS), São Par lo.

1 Johnson, Robert W., Administração Financeira, vol. 1, São Paulo, Livraria Pioneira Editôra, 1967, Capítulo 1..$^{\circ}$ A Função do Administrador Financeiro, Capítulo 2. , O Dilema do Administrador: Liquidez vs. Rentabilidade. 
não manter o equilíbrio entre o objetivo da liquidez e o da retôrno-rentabilidade.

No Brasil, o divórcio entre a tesouraria e a contadoria é visto, freqüuentemente, na prática da administração financeira. A justificativa desta separação quase sempre foi o impacto inflacionário na administração financeira. A excessiva ênfase na manutenção da liquidez, numa época inflacionária, motivava a descapitalização da emprêsa em muitos casos. A excessiva ênfase na rentabilidade, baseada numa equação entre preços e custos, levava a emprêsa a dificuldades monetárias. Agora, uma vez que o Brasil caminha para uma relativa estabilidade financeira, as emprêsas deverão reexaminar suas políticas e estrutura financeira para obter máxima satisfação dos recursos disponíveis.

O fluxo de fundos (caixa e capital de giro), neste sentido, tem sido considerado um importante método por apresentar uma visão integrada de liquidez e rentabilidade, quando sua apresentação fôr feita de maneira apropriada, vinculada à Demonstração de Lucros e Perdas. Os estudiosos norte-americanos têm advogado a inclusão do fluxo de fundos como um relatório financeiro necessário para o relatório anual submetido à Assembléia de Acionistas. ${ }^{2}$ O presente artigo abrangerá o esquema de preparação de um relatório que combina:

- o resultado econômico refletido em Demonstração de Lucros e Perdas;

- o resultado monetário contido no Fluxo de Caixa; e - o resultado de recursos financeiros através do Fluxo de Fundos.

\footnotetext{
- KoHLER, Eric L., Accounting for Management, Englewood Cliffs, N. J. Prentice-Hall, Inc., 1965, Capítulo 14, Flow Statements.

Refletindo êste pensamento já em 1962 o Prof. JACK KEMPNER, então Consultor Técnico da Escola de Administração de Emprêsas da Fundação Getálio Vargas, contribuiu com um artigo, Contrôle Financeiro Através da Análise do Fluxo de Fundos nesta Revista (Vol. 2, n. ${ }^{\circ}$, maio/agôsto de 1962, p. 22 a 43 ).
} 
Como exemplo, a Companhia A apresenta o seguinte balanço comparativo do determinado exercício:

(em NCr\$)

Caixa

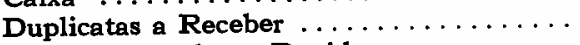

Prov. p/Devedores Duvidosos

Estoque de Mercadorias .............

Seguros Pagos Antecipadamente .......

Ativo Circulante $\ldots \ldots \ldots \ldots \ldots \ldots \ldots$

Terrenos $\ldots \ldots \ldots \ldots \ldots \ldots \ldots \ldots \ldots$

Edifícios e Equipamentos: *

Custos $\ldots \ldots \ldots \ldots \ldots \ldots \ldots \ldots$
Prof. p/depreciação $\ldots \ldots \ldots \ldots \ldots$

Fornecedores a Pagar .............

Contas a Pagar - Desp. Oper. .......

Impôsto de Renda a Pagar ..........

Empréstimos Bancários a Curto Prazo ..

Dividendos a Pagar ...............

Credores Diversos - Diretores ........

Passivo Circulante ................

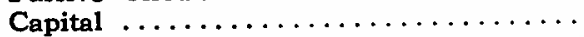

Lucros Retidos $* * \ldots \ldots \ldots \ldots \ldots \ldots$
Balanço Inicial

Balanço Final

\begin{tabular}{|c|c|c|c|}
\hline $\begin{array}{r}2.280 \\
110\end{array}$ & $\begin{array}{r}500 \\
2.170\end{array}$ & $\begin{array}{r}2.930 \\
130\end{array}$ & $\begin{array}{l}1.400 \\
2.800\end{array}$ \\
\hline & $\begin{array}{r}4.540 \\
170\end{array}$ & & $\begin{array}{r}4.830 \\
110\end{array}$ \\
\hline & $\begin{array}{r}7.380 \\
750\end{array}$ & & $\begin{array}{r}9.140 \\
750\end{array}$ \\
\hline $\begin{array}{r}17.100 \\
6.230\end{array}$ & 10.870 & $\begin{array}{r}18.150 \\
6.740\end{array}$ & 11.410 \\
\hline & 19.000 & & 21.300 \\
\hline & $\begin{array}{r}1.500 \\
\mathbf{3 0 0} \\
\mathbf{5 8 0} \\
\mathbf{4 0 0} \\
\mathbf{5 0 0} \\
\mathbf{5 0 0}\end{array}$ & & $\begin{array}{r}1.300 \\
360 \\
380 \\
280 \\
700 \\
660\end{array}$ \\
\hline & $\begin{array}{r}3.780 \\
10.000 \\
5.220\end{array}$ & & $\begin{array}{r}3.680 \\
10.000 \\
7.620\end{array}$ \\
\hline & 19.000 & & 21.300 \\
\hline
\end{tabular}

A Demonstração de Lucros e Perdas da Companhia A do mesmo exercício, apresenta o seguinte resultado:

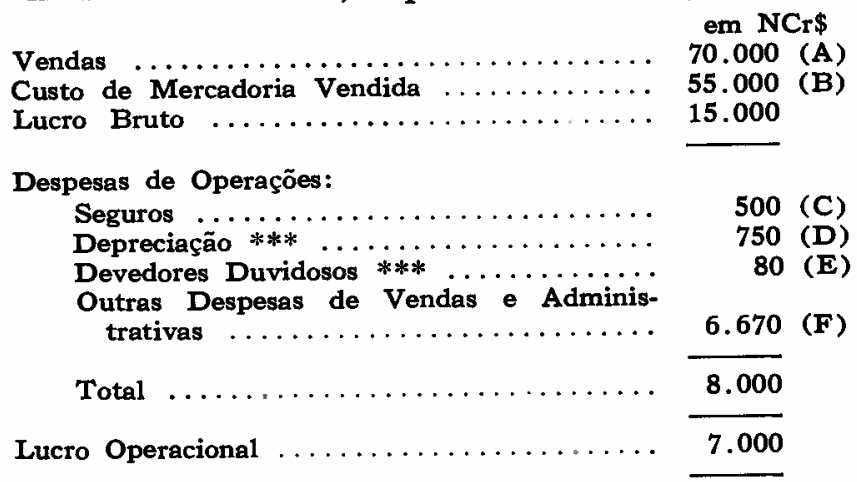

* Aquisição de novos equipamentos de $\mathrm{NCr} \$ 1.350$ durante o exercício. ** Dividendos Declarados: NCr\$1.340

Remuneração da Diretoria: $15 \%$ sôbre o lucro líquido do exercício. 
Itens Não Operacionais:

Ganho Sôbre Venda de Ativo Fixo ..... + 100 (G)

Despesas com Juros ............. -900 (H)

Total

$-800$

Lucro Antes do Impôsto de Renda ....... 6.200

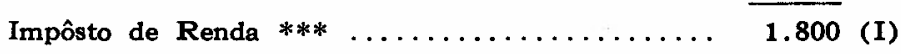

4.400

Primeiramente, vamos converter a Demonstração de Lucros e Perdas no fluxo de caixa. Para facilitar a explicação, identificamos os itens da Demonstração de Lucros e Perdas com as letras (A) a (I).

$\begin{array}{ll}\mathbf{N C r} \$ & \mathbf{N}\end{array}$

2.280

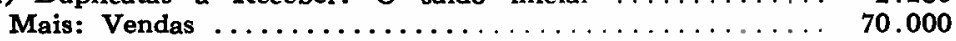

Total a Receber de Clientes .................. 72.280

Menos: Duplicatas a Receber: o saldo final ......... 2.930

Total de Baixa de Duplicatas a Receber ........... 6.

Menos: Baixa de Devedores Incobráveis - Ver (E) .... 60

Cobrança do Exercício $\ldots \ldots \ldots \ldots \ldots \ldots \ldots \ldots \ldots \ldots . \ldots \ldots 9 . \ldots \ldots$

NCr\$

Item (B) Custo de Mercadoria Vendida .............. 55.000

Menos: Estoque Inicial $\ldots \ldots \ldots \ldots \ldots \ldots \ldots \ldots \ldots \ldots \ldots \ldots \ldots \ldots \ldots$

Mercadoria Comprada e Vendida dentro dêste Exercício .. 50.460

Mais: Estoque Final $\ldots \ldots \ldots \ldots \ldots \ldots \ldots \ldots \ldots \ldots \ldots \ldots \ldots .4 .830$

Compras do Exercicio ....................... 55.290

Fornecedores a Pagar: o saldo inicial ... . . . . . . . 1.500

Mais: Compras do Exercício ................. 55.290

Total de Obrigações a Pagar a Fornecedores ......... 56.790

Menos: Fornecedores a Pagar: o saldo final .......... 1.300

Pagamentos a Fornecedores .................. $\overline{\mathbf{5 5 . 4 9 0}}$

NCr\$

Item (C) Despesas de Seguros $\ldots \ldots \ldots \ldots \ldots \ldots \ldots \ldots \ldots \ldots$

Menos: Seguros Pagos no Exercício Anterior, mas considerados como despesas dêste exercício ............ 170

Seguros Pagos e Incorridos dentro dêste exercício . . . . . . . $\quad 330$

Mais: Seguros Pagos neste exercício, mas que serão considerados como despesas no exercício futuro ............ 110

Seguros Pagos $\ldots \ldots \ldots \ldots \ldots \ldots \ldots \ldots \ldots \ldots \ldots \ldots \ldots \ldots$

*** Provisionamentos 
Item (D) A despesa de depreciação é uma despesa "provisionada" e, portanto, não necessita de desembôlso de caixa.

Item (E) A despesa com devedores duvidosos também é uma despesa "provisionada" e, portanto, não necessita de desembôlso de caixa. Entretanto, observamos no Balanço comparativo um aumento de sòmente NCr\$ 20 na Provisão para Devedores Duvidosos, enquanto o provisionamento de despesas de devedores duvidosos foi de $\mathrm{NCr} \$ 80$. Isto indica que houve a baixa de duplicatas incobráveis de NCr\$60. A conta "T" da Provisão para Devedores Duvidosos deveria ter sido assim movimentada:

\begin{tabular}{|c|c|c|c|c|c|}
\hline \multicolumn{6}{|c|}{ Provisão para Devedores Duvidosos } \\
\hline \multirow[t]{3}{*}{$\begin{array}{l}\text { Baixa de Duplicatas Inco- } \\
\text { bráveis } \\
\text { Saldo }\end{array}$} & $\mathrm{NCr} \$$ & $\begin{array}{r}60 \\
130\end{array}$ & $\begin{array}{l}\text { Saldo Inicial } \\
\text { Provisionamento } \\
\text { Dêste Exercício. }\end{array}$ & NCr\$ & $\begin{array}{r}110 \\
80\end{array}$ \\
\hline & $\mathrm{NCr} \$$ & 190 & & $\mathrm{NCr} \$$ & 190 \\
\hline & & & Saldo Final & NCr\$ & 130 \\
\hline
\end{tabular}

$\mathrm{NCr} \$$

Item (F) Despesas Incorridas no Exercicio Anterior Pagas neste

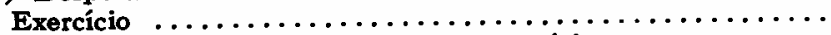
Mais: Despesas Incorridas neste Exercício $\ldots \ldots \ldots \ldots \ldots$

Total de Obrigações a Pagar de Despesas e Administrativas

Menos: Despesas Incorridas neste Exercício mas que serão

Pagas no Exercício Futuro .................. 360

Pagamentos de Despesas de Vendas e Administrativas .... 6.610

Item (G) Somando-se o custo de novos equipamentos de $\mathrm{NC}$ \$ $\$ 1.350$, adquiridos neste exercício, ao saldo inicial de $\mathrm{NCr} \$ 17.100$, o saldo final deveria ser de NCr\$18.450. Entretanto, o Balanço final dá o saldo de NCr $\$ 18.150$. Isto significa que houve a baixa de ativo cujo custo foi de NCr $\$ 300$ (NCr\$ 18.450 - NCr $\$ 18.150$ ).

Paralelamente, a Provisão para Depreciação também deverá ter sido afetada pela baixa do ativo. Assim, a conta "T" desta provisão seria:

\begin{tabular}{|c|c|c|c|c|c|}
\hline \multicolumn{6}{|c|}{ Provisão para Depreciação } \\
\hline $\begin{array}{l}\text { Estôrno da Provisão } \\
\text { Referente ao Ativo } \\
\text { Baixado }\end{array}$ & $\mathrm{NCr} \$$ & 240 & $\begin{array}{l}\text { Saldo Inicial } \\
\text { Provisionamento } \\
\text { Dêste Exercício }\end{array}$ & $\mathrm{NCr} \$$ & $\begin{array}{r}6.230 \\
750\end{array}$ \\
\hline \multirow[t]{2}{*}{ Saldo } & & 6.740 & & $\mathrm{NCr} \$$ & 6.980 \\
\hline & NCr\$ & 6.980 & Saldo Final & $\mathrm{NCr} \$$ & 6.740 \\
\hline
\end{tabular}


Assim, chegamos à seguinte conclusão sôbre o ganho de venda de ativo fixo.

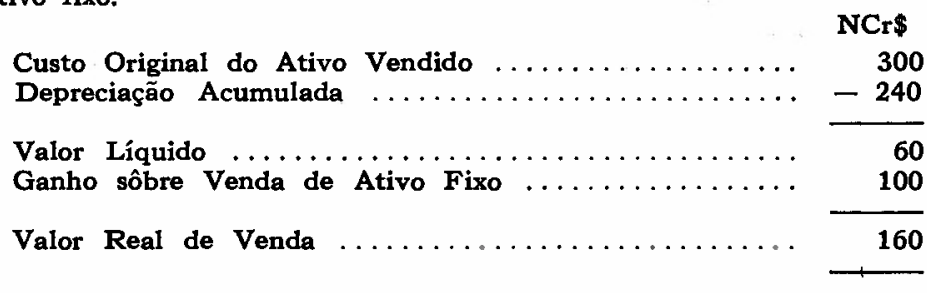

Item (H) Desde que no Balanço não constam Juros Antecipadamente Pagos nem Juros a Pagar, a despesa do exercício de NCr\$ 900 é considerada inteiramente paga durante êste exercício.

NCr\$

Item (I) Impôsto de Renda do Exercício Anterior Pago neste Exercício Mais: Impôsto de Renda Provisionado neste Exercício ....

Total de Obrigações de Impôsto de Renda a Pagar ......

Menos: Impôsto de Renda Provisionado Neste Exercício,

Analisamos acima, conforme identificados de (A) a (I), todos os itens de Demonstração de Lucros e Perdas em sua relação ao Fluxo de Caixa. Uma grande parte dos itens do Balanço foi também considerada nesse processo de conversão ao Fluxo de Caixa. Restam três itens no Balanço que não se vinculam com os itens de Demonstração de Lucros e Perdas, ou sejam:

\section{- Empréstimos Bancários a Curto Prazo \\ - Dividendos a Pagar \\ - Credores Diversos-Diretores}

Analisamos, a seguir, êstes três itens com as siglas $(J)$, (K) e (L).

Item (J) Empréstimos Bancários a Curto Prazo

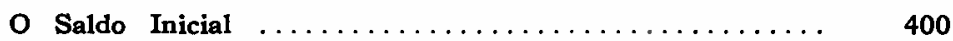

o Saldo Final $\ldots \ldots \ldots \ldots \ldots \ldots \ldots \ldots \ldots \ldots \ldots \ldots \ldots, \quad 280$

Pagamentos de Empréstimos $\ldots \ldots \ldots \ldots \ldots \ldots \ldots \ldots \ldots . \ldots \ldots$

Certamente, o valor acima de NCr\$120 refere-se ao valor líquido, ou seja, empréstimos pagos menos empréstimos obtidos.

Itens (K) Dividendos a Pagar

e (L) Credores Diversos - Diretores 
Os dois itens acima movimentam-se conforme a decisão da Assembléia de Acionistas sôbre a disposição de lucro do exercício. A conta Lucros Retidos foi assim movimentada:

\begin{tabular}{|c|c|c|c|c|c|}
\hline \multicolumn{6}{|c|}{ Lucros Retidos } \\
\hline \multirow{3}{*}{$\begin{array}{l}\text { Remuneração da Dire- } \\
\text { toria } \\
\text { Dividendos Declarados } \\
\text { Saldo }\end{array}$} & NCr\$ & 660 & $\begin{array}{l}\text { Saldo Inicial } \\
\text { Lucro do Exercício }\end{array}$ & $\mathrm{NCr} \$$ & $\begin{array}{l}5.202 \\
4.400\end{array}$ \\
\hline & & $\begin{array}{l}1.340 \\
7.620\end{array}$ & & $\mathrm{NCr} \$$ & 9.620 \\
\hline & $\mathrm{NCr} \$$ & 9.620 & Saldo Final & $\mathrm{NCr} \$$ & 7.620 \\
\hline
\end{tabular}

Conseqüentemente, as duas contas em questão (Dividendos a Pagar e Credores Diversos-Diretores) mostram os seguintes movimentos:

\begin{tabular}{|c|c|c|c|c|c|}
\hline \multicolumn{6}{|c|}{ Dividendos a Pagar } \\
\hline \multirow[t]{3}{*}{$\begin{array}{l}\text { Dividendos Pagos } \\
\text { Saldo }\end{array}$} & NCr\$ & $\begin{array}{r}1.140 \\
700\end{array}$ & \multirow[t]{2}{*}{$\begin{array}{l}\text { Saldo Inicial } \\
\text { Dividendos Declarados }\end{array}$} & $\mathrm{NCr} \$$ & $\begin{array}{r}500 \\
1.340\end{array}$ \\
\hline & \multirow{2}{*}{\multicolumn{2}{|c|}{ NCr $\$ 1.840$}} & & NCr\$ & 1.840 \\
\hline & & & Saldo Final & $\mathrm{NCr} \$$ & 700 \\
\hline \multicolumn{6}{|c|}{ Credores Diversos-Diretores } \\
\hline \multirow[t]{3}{*}{$\begin{array}{l}\text { Pagamentos aos Dire- } \\
\text { tores } \\
\text { Saldo }\end{array}$} & $\mathrm{NCr} \$$ & $\begin{array}{l}500 \\
660\end{array}$ & \multirow[t]{2}{*}{$\begin{array}{l}\text { Saldo Inicial } \\
\text { Remuneração da Dire- } \\
\text { toria }\end{array}$} & NCr\$ & \\
\hline & \multirow{2}{*}{\multicolumn{2}{|c|}{$\mathrm{NCr} \$ 1.166$}} & & $\mathrm{NCr} \$$ & 1.160 \\
\hline & & & Saldo Final & NCr\$ & 660 \\
\hline
\end{tabular}

Apresentamos, no Quadro 1, a demonstração consolidada de resultados econômico (Lucros e Perdas) e monetário (Fluxo de Caixa). Esta demonstração nìtidamente oferece resposta à pergunta: Por que o aumento de caixa foi tão pouco, embora o resultado do exercício tenha sido ótimo? 


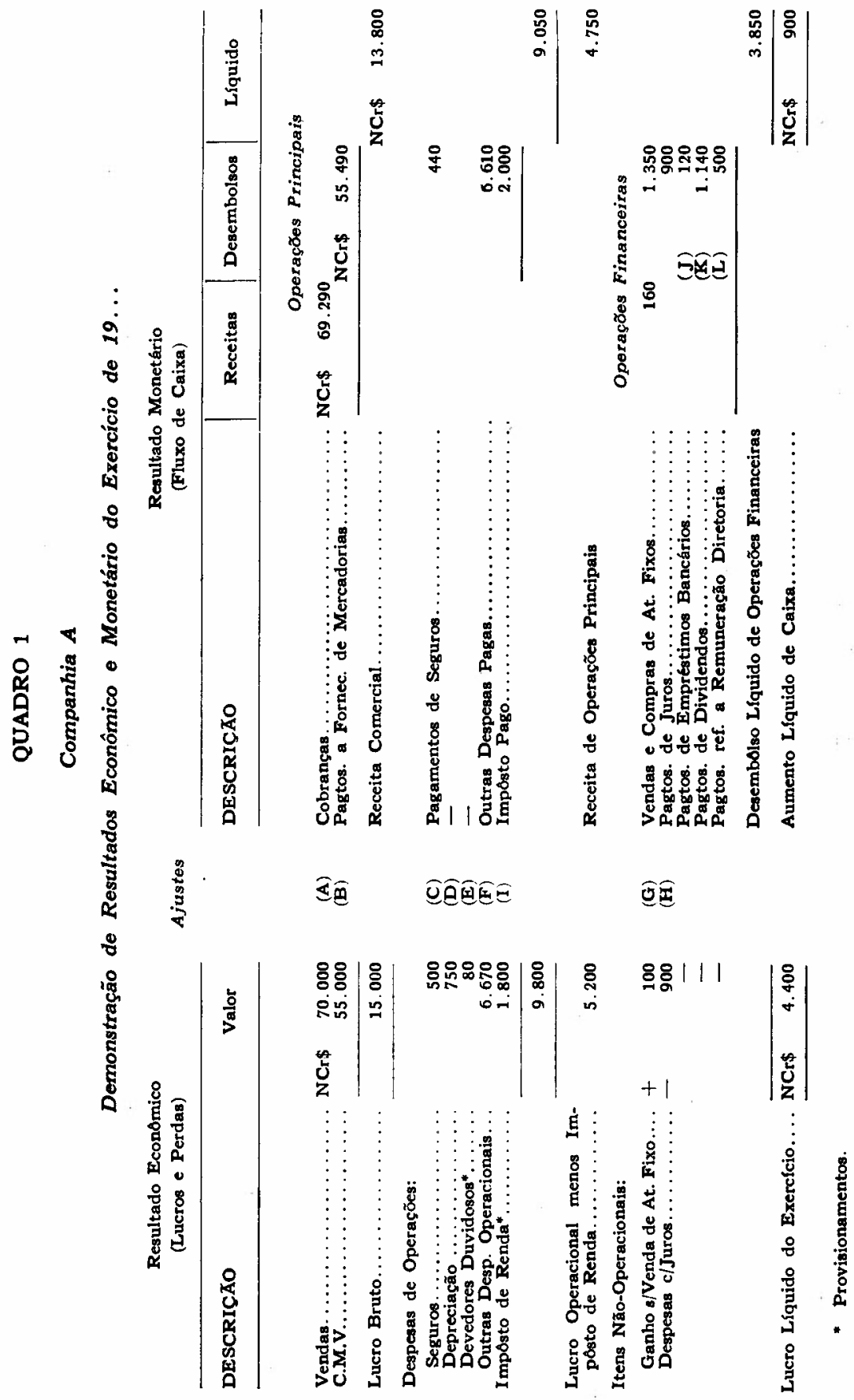


O cash (caixa e bancos), indubitàvelmente, é um dos mais importantes itens de recursos financeiros da emprêsa. O crédito que fornecedores proporcionam na compra de mercadorias é também considerado como uma fonte de recursos financeiros. $O$ crédito que a emprêsa concede a seus clientes representa a utilização de tais recursos.

A fonte mais importante de recursos financeiros da emprêsa é, portanto, o lucro oriundo de operações. Vamos, então, analisar os recursos financeiros adicionais criados através de atividades econômicas da emprêsa:

Operações Principais

Fontes Utilização Efeito

Líquido

NCr\$ NCr\$ NCr\$

Vendes

70.000

Menos: Baixas de Devedores Incobráveis .....

C.M.V.

(60)

Aumento Líquido de Recursos através de Trans. Comerciais $\ldots \ldots \ldots \ldots \ldots \ldots \ldots \ldots \ldots$.

Despesas de Operações:

Seguros

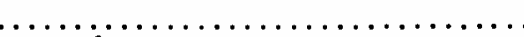

Depreciação — E uma despesa que não necessita de utilização de fundos.

Devedores Duvidosos - Aumento Líquido ....

Outras Despesas Operacionais ............

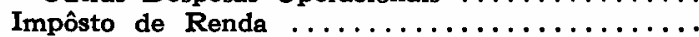

$\mathbf{5 5 . 0 0 0}$

14.940

500

20

6.670

1.800

8.990

Aumento Líquido de Recursos Através de Oper. Principais

Operaçōes Financeiras

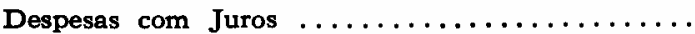

Vendas e Compras de Ativos Fixos ...........

Dividendos Declarados ................

Remuneração da Diretoria...$\ldots \ldots \ldots \ldots \ldots$.

Aumento Líq. de Recursos através de Ativid. Eco-

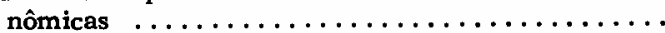


E importante observar no quadro anterior que, em comparação com o fluxo de caixa, o movimento de recursos financeiros (o Fluxo de Fundos) reflete o resultado de operações na base de transações incorridas (accrual basis), ao invés de acôrdo com incidências de recebimentos e desembolsos monetários (cash basis).

O aumento líquido de recursos financeiros através de atividades econômicas de $\mathrm{NCr} \$ 1.860$ significa o aumento de capital de giro. Do Balanço Comparativo preparamos o seguinte quadro sôbre as aplicações de recursos financeiros de operações para a formação do aumento do capital de giro:

Aumento do Capital de Giro

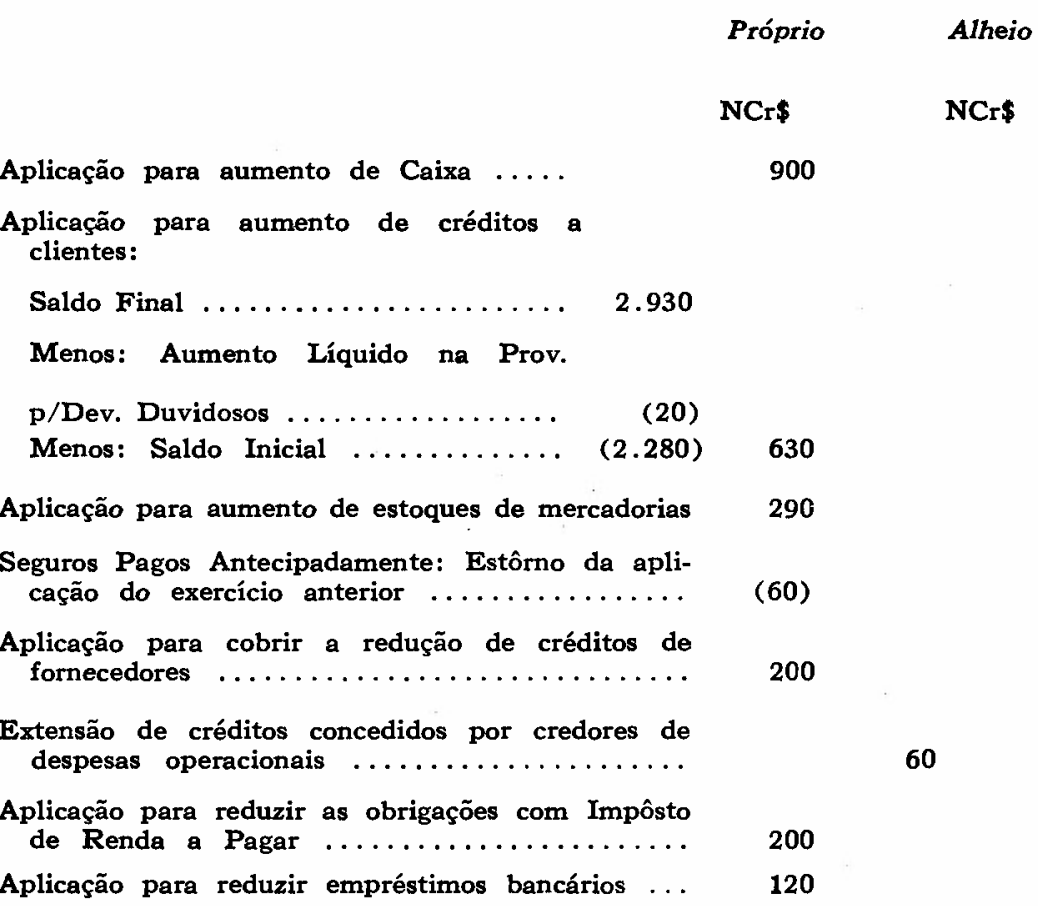




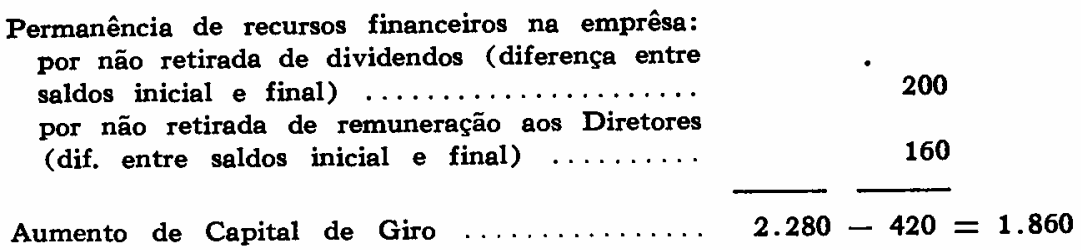

O fluxo de caixa respondia à pergunta: Por que o aumento de caixa foi tão pouco, embora o resultado do exercício tenha sido ótimo? Agora, então, a segunda pergunta é: Onde foi o resto do lucro? $O$ fluxo de fundos responde a esta pergunta - uma grande parte para o aumento de outros itens do capital de giro e outra para os itens não circulantes, principalmente ativos fixos e a disposição dos lucros retidos.

Resumidos, no Quadro 2, Demonstração Integrada de Resultados Econômico, Monetário e de Recursos Financeiros, os três resultados, interligando-os:

- o resultado econômico refletido em Demonstração de Lucros e Perdas;

- o resultado monetário contido no Fluxo de Caixa; e - o resultado de recursos financeiros através do Fluxo de Fundos.

A função principal dêste quadro, conforme comentamos no início dêste artigo, é demonstrar à alta administração da emprêsa um retrato do resultado de rentabilidade e liquidez financeiras, simultâneamente na forma simples e consolidada.

A técnica apresentada neste artigo, naturalmente, não sòmente poderá ser útil à análise financeira do passado, mas, também, à análise integrada do orçamento financeiro. 


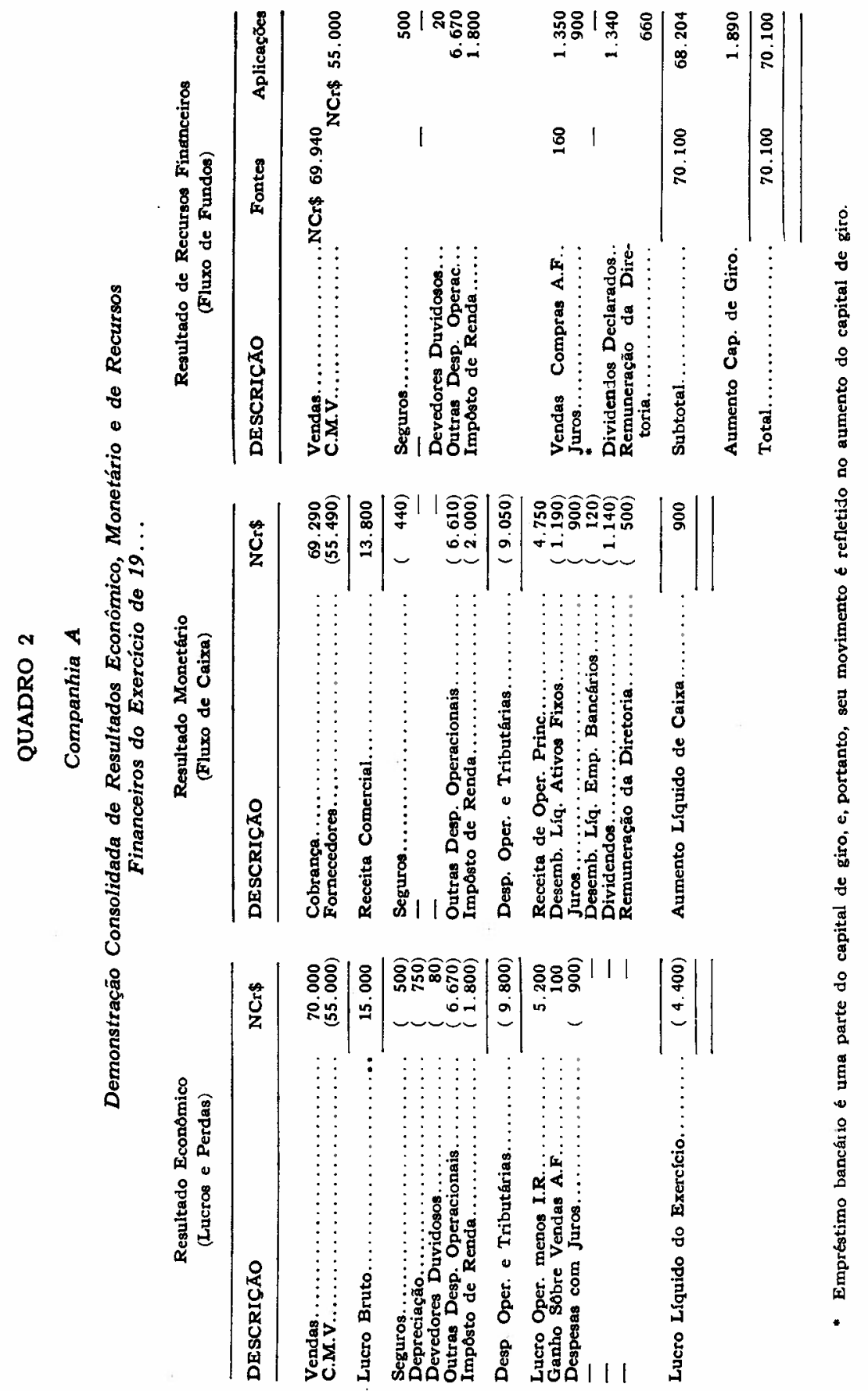




\section{OBSERVAÇÕES BIBLIOGRAFICAS}

Em adição aos livros e artigos citados nas notas de rodapé dêste artigo, recomendamos a leitura:

- do Capitulo 8. , The Flow of Cash, de Managerial Accounting, dos Professôres JAEdicke e MOoRE, Chicago, E.U.A., South-Western Publishing Co., 1963.

- também, Accounting Flows: Income, Funds and Cash, dos Professôres JAEdicke e Sprouse (Englewood Cliffs, N. J., E.U.A., Prentice-Hall, Inc., 1965) é excelente.

- O Instituto Americano de Contadores Públicos Certificados (AICPA) publicou duas obras sôbre os fluxos de caixa e de fundos: Cash Flow Analysis and the Funds Statement (1961) e The Statement of Source and Application of Funds (1963). Consideramos o Relatório de Pesquisa N. ${ }^{\circ} 38$ da Associação Americana de Contadores (NAA), Cash Flow Analysis for Managerial Control (1961), mais analítico e prático para administradores de emprêsas.

- Existem monografias ótimas sôbre o assunto, publicadas pela INTERCollegIATE CASE Clearing House da Universidade de Harvard, por exemplo: ICH $10 \mathrm{C}$ 41. Introduction to Cash Flows and Income Measurement ( 5 páginas).

ICH $10 \mathrm{C}$ 92. Note on the Funds Flow Statement (12 páginas).

ICH $10 \mathrm{C}$ 2. Cash Flow and Fund Flow Statements (24 páginas e cinco exercícios). 